\title{
Longitudinal study of behaviour disorders in low birthweight infants
}

\author{
C J Stevenson, P Blackburn, P O D Pharoah
}

\begin{abstract}
Aim-To compare the prevalence of childhood and adolescent behavioural problems in low birthweight infants with matched controls.

Methods-A cohort study of a geographically defined population of survivors of $\leqslant 1500 \mathrm{~g}$ birthweight born in 1980 and 1981 and age, sex, and school matched controls was undertaken. Children with a clinical disability were excluded. Data from Rutter questionnaires, completed by parents and teachers when the children were aged 8 and again at age 14 years, were assessed. Results-From an initial 40321 births in 1980-81 there were 399 of birthweight $\leqslant 1500 \mathrm{~g}$, of whom 219 survived to age 8 . After exclusion of the 42 children with clinical disability, 177 cases comprised the sample. Of these, $10(6 \%)$ refused or could not be contacted, leaving 167 cases for each of whom a matched control was obtained. At age 14 years, both parent and teacher questionnaires showed an increased prevalence of behavioural problems in cases compared with controls. The presence of a pervasive behavioural problem, when the responses of parents and teachers were concordant, was present in $9 \%$ of cases and $3 \%$ of controls. There were 132 pairs where the cases and controls were the same at ages 8 and 14 years and provided longitudinal data. The parental questionnaire showed there was a significant decrease in the prevalence of behavioural problems for cases and controls between the ages of 8 and 14 years. There was almost no longitudinal change in the prevalence of behavioural problems as shown by the teacher questionnaires.

Conclusion-Although low birthweight infants are at increased risk of behavioural problems, because they comprise only a small proportion of all births, their population attributable risk for behavioural disorder is around $2-3 \%$.
\end{abstract}

(Arch Dis Child Fetal Neonatal Ed 1999;81:F5-F9)

Foundation for the Study of Infant Deaths Unit of Perinatal and Paediatric

Epidemiology

Department of Public

Health

University of Liverpool

Liverpool L69 3GB

C J Stevenson

P Blackburn

P O D Pharoah

Correspondence to: Emeritus Professor P O D Pharoah.

Accepted 9 December 1998

have improved as neonatal intensive care has evolved. ${ }^{1-5}$ Although studies have found no evidence of an increased prevalence of severe disability, ${ }^{6-8}$ the quality of life of all survivors remains a cause for concern.

Most earlier outcome studies of very low birthweight (VLBW) infants have been limited to an assessment of the prevalence of clinical disabilities or to measures of cognitive and motor performance. More recently attention been given to behavioural issues, and reports have addressed aspects of behavioural problems in low birthweight infants, such as prevalence $^{9}$ and the tools of measurement, ${ }^{10}$ patterns of neuropsychological function, ${ }^{11}$ neurodevelopmental outcome, ${ }^{12}$ associations with IQ, language and other skills, ${ }^{13}$ and factors contributing to behavioural outcome, such as cerebral damage and social environment. ${ }^{14} 15$

A review of published reports between 1989 and 1992 on the long term prognosis of extremely low birthweight infants (ELBW) showed that, despite normal IQs, $60-70 \%$ experience problems at school. Many of the children have cognitive, perceptual, and motor deficits combined with behavioural problems, referred to as "the new morbidities." morbidities have been defined as the combination of psychosomatic symptoms, such as sleeping problems, lack of appetite, and headache, with psychomotor features, such as overactivity, poor concentration, tendency to tire easily, and behavioural disturbances.

Interest has been growing in identifying the prevalence of subtle longterm morbidities, or new morbidities. A review of follow up studies of VLBW and ELBW infants to school age included minor neurodevelopmental abnormalities, motor delay, and behavioural problems. To identify these morbidities, gross IQ measures may not be useful as most VLBW and ELBW infants are of average IQ. ${ }^{17}$ The review concludes that there is a need for the more subtle difficulties to be defined and specifically assessed, and as these difficulties may not manifest themselves in infancy and early childhood, it becomes increasingly important to follow up prematurely born infants to school age and beyond.

A cohort of low birthweight infants born in 1979, 1980, and 1981 was assessed for clinical disability at the age of 3 years. A subsample of this cohort was reassessed when aged 8 years. ${ }^{6918}$ Rutter behavioural questionnaires ${ }^{19-21}$ for parents and teachers were administered for those children whose birthweights were less than or equal to $1500 \mathrm{~g}$ (VLBW) and matched with controls at age 8 years. ${ }^{9}$ A longitudinal follow up of this cohort is reported here, along with the findings from Rutter questionnaires administered to parents and teachers for the same VLBW cases and controls at age 14 years.

\section{Methods}

Data from all infants weighing $\leqslant 1500 \mathrm{~g}$ at birth, and born in 1980 and 1981 to mothers who resided at the time of the birth in the five 
health districts of the county of Merseyside, were obtained from birth notifications. The obstetric and neonatal records were abstracted for demographic and clinical details of the mother, and birthweight and head circumference of the child. The infants had been examined at the age of 3 years to determine the prevalence of disability and at 8 years to determine the prevalence of subclinical deficits of cognitive and motor function and of behavioural disorders. ${ }^{6918}$

At the 8 year follow up, an age and sex matched control from the same school was also assessed, for those children attending normal schools. The birthweight of each control was obtained from a questionnaire completed by a parent. Matching for school was done because primary schools tend to draw children from socially homogenous areas, thus creating an effective match for important social variables. This premise was tested at the 8 year follow up, when cases and controls were compared for several socioeconomic variables, including social class, current employment status of the father, housing status of the family, parental education and income and the number of children in the family. All these indices were marginally in favour of better social circumstances for the controls, but none was significant. The only significant difference was that fewer cases than controls were living with both natural parents. ${ }^{18}$ The birthweight of each control was obtained by questioning the mother.

The children were re-assessed when aged 14 years with the same controls, when possible, as at the 8 year follow up. The children have since moved from primary to secondary schools and the controls were not always at the same school as the index child. If the original control was not available, a new control of the same sex, in the same class at secondary school and nearest in birth date to the index child was selected.

Children with a disability were excluded from the analysis. Disability was defined by clinical criteria and included those children with a diagnosis of cerebral palsy; hearing loss that necessitated the use of a hearing aid or admission to a school for the deaf; visual acuity of less than $6 / 12$ in the better eye or a visual defect sufficient to necessitate special schooling; a learning disability requiring attendance at a special school; and epilepsy.

The behaviour of the children was assessed using Rutter screening questionnaires which were completed by parents and teachers. The index and control children were visited either at school or at home. If the child was seen at school, the Rutter teacher questionnaire was given to the child's teacher to be completed

Table 1 Case control comparison of type of behaviour problem aged 14 years

\begin{tabular}{lcclcc}
\hline \multirow{2}{*}{$\begin{array}{l}\text { Type of behavioural } \\
\text { problem }\end{array}$} & \multicolumn{2}{l}{ Parent questionnaire } & & \multicolumn{2}{l}{ Teacher questionnaire } \\
\cline { 2 - 3 } \cline { 5 - 6 } \cline { 5 - 6 } & Cases n (\%) & Controls n (\%) & & Cases n (\%) & Controls n (\%) \\
\hline None & $126(75 \%)$ & $144(86 \%)$ & & $127(76 \%)$ & $148(89 \%)$ \\
Emotional & $20(12 \%)$ & $6(4 \%)$ & & $12(7 \%)$ & $5(3 \%)$ \\
Conduct & $15(9 \%)$ & $6(4 \%)$ & & $20(12 \%)$ & $10(6 \%)$ \\
Undifferentiated & $5(3 \%)$ & $4(2 \%)$ & & $5(3 \%)$ & $1(1 \%)$ \\
Missing data & $1(1 \%)$ & $7(4 \%)$ & & $3(2 \%)$ & $3(2 \%)$ \\
Total & $167(100 \%)$ & $167(100 \%)$ & & $167(100 \%)$ & $167(100 \%)$ \\
\hline
\end{tabular}

and returned usually by post. The Rutter parent questionnaire was given either to the parent if present at the interview, or sent home with the child. If the child was seen at home, the parent completed the Rutter parent questionnaire and the Rutter teacher questionnaire was taken to school by the child for completion by the teacher.

The teacher component of the Rutter behaviour scale consists of 26 brief statements each of which is scored 0,1 , or 2 , producing a total score within the range 0 to 52 . A total score $\geqslant 9$ indicates a behavioural problem. ${ }^{19}$

The Rutter behaviour scale for parents comprises 32 statements concerning the child's behaviour. The prevalence of the behaviour, or the degree of its severity, or the extent to which the statement applies to the child is scored 0,1 , or 2 , producing a total score within the range of $0-64$. A total score $\geqslant 13$ indicates a behavioural problem. ${ }^{2021}$

In some instances not all 32 items on the parent questionnaire or the 26 items on the teacher questionnaire were completed. Children were included in the analyses if at least 30 items on the parent, and 24 items on the teacher, questionnaire had been completed.

Three items (restlessness, fidgeting, not settling to activities) each on the teacher and the parent Rutter questionnaires enable the child to be categorised as hyperactive. A score of at least 3 out of 6 on both teacher and parent questionnaires is required for the child to be considered hyperactive.

In addition, the Conners scale, ${ }^{22}$ modified by Taylor and Sandberg, ${ }^{23}$ was used for the assessment of hyperactivity. The mean score is taken from eight questions, and, if over 1.5, hyperactivity is indicated.

The $\chi^{2}$ test with Yates' correction for $2 \times 2$ contingency tables, Fisher's exact test, $\mathrm{McNe}$ mar's test and the $t$ test for the difference between two proportions were used

\section{Results}

There were 40321 live births in Merseyside in 1980-81; 397 were of birthweight $\leqslant 1500 \mathrm{~g}$, of whom 219 survived to age 15 years. Of the 219 survivors, $12(5 \%)$ refused assessment, were untraced, or had moved abroad. Twenty seven $(12 \%)$ children with a disability and attending special schools and $13(6 \%)$ with a disability attending mainstream schools were not included in the assessment of behavioural disorders. This report is of 167 children classified as having no disability $(77 \%$ of the 219 survivors of birthweight $<1500 \mathrm{~g}$ ) and their matched controls.

A flow chart depicting the selection of the study sample and the proportions successfully followed up and assessed is shown in fig 1. An important feature of the study was the high (94\%) follow up rate achieved.

The mean birthweight of the 167 nondisabled index cases was $1259 \mathrm{~g}$ (range 630-1500 g) and $3352 \mathrm{~g}$ (range 2098-4550 g) for the controls. The gestational age of the index cases ranged from 26 to 37 weeks, with a mean of 30.8 weeks. Data on the gestational age of the controls were not obtained, but the 


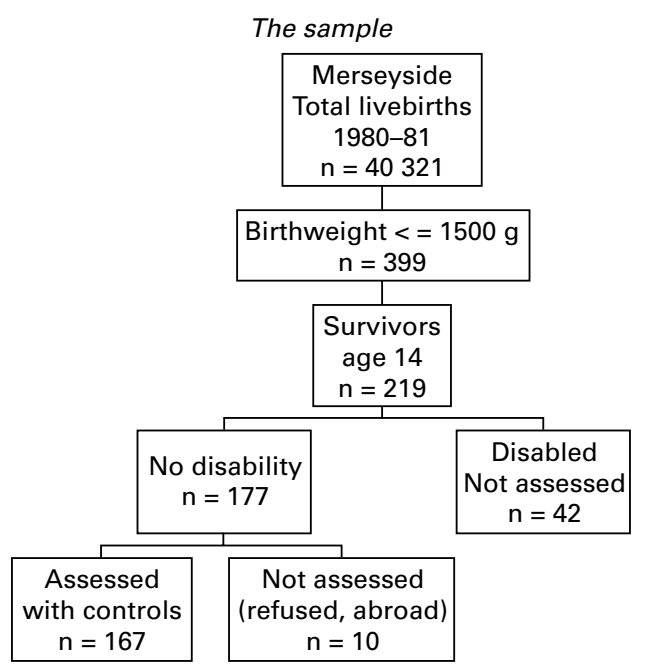

Figure 1 Flow chart depicting selection of study sample and proportions successfully followed up and assessed.

mean and range of birthweight indicated that most must have been term infants.

Thirty one $(18.6 \%)$ of the 167 non-disabled cases were from twin pregnancies whereas all the controls were from singleton pregnancies. There were highly significant differences between the cases and their matched controls in height, weight, body mass index and head circumference, with the cases being smaller for all parameters. These data have been reported before. $^{24}$

BEHAVIOURAL PROBLEMS IN CASES AND CONTROLS AT 14 YEARS OF AGE

The prevalence and the type of behavioural problem classified in two birthweight groups is shown in table 1. For the whole sample of birthweight $\leqslant 1500 \mathrm{~g}$, comparison of the casecontrol pairs at age 14 years showed that $40 / 166(24 \%)$ cases and 16/160 (10\%) controls had a behavioural problem on the parental questionnaire. On the teacher questionnaire the proportions were $37 / 164(23 \%)$ and $16 / 164(10 \%)$, respectively. These differences between cases and controls were highly significant $(p<0.01)$. On the basis of this screening, both emotion and conduct disorders were more common among cases than controls.

In both the cases and controls the parent questionnaire was more likely than the teacher questionnaire to indicate the presence of a behavioural problem. The concordance be-

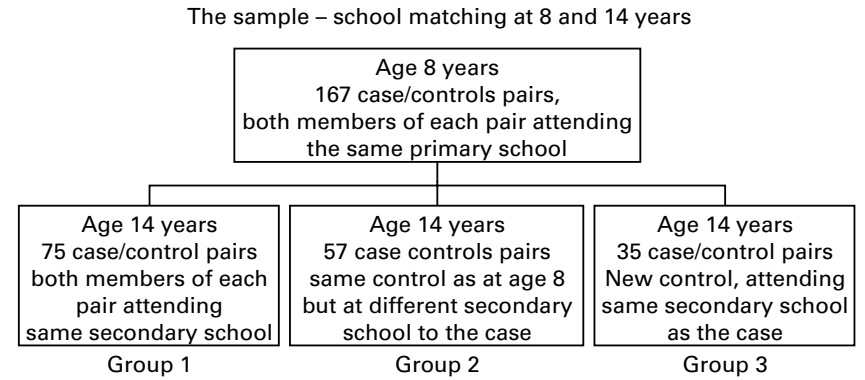

Groups 1, 2, and 3 comprise the sample for the case/control comparison at age 14/15 years Groups 1 and 2 comprise the sample for the longitudinal case/control comparison

Figure 2 School derivation of pairs for whom longitudinal data were available. tween parent and teacher as to whether or not a behavioural problem was present was $71.4 \%$ for the cases and $86.4 \%$ for the controls.

Children with a pervasive problem are those who have a high score on both parent and teacher questionnaires. This was present in $9 \%$ of cases and $3 \%$ of controls.

\section{HYPERACTIVITY}

The differences in the proportion of hyperactive children among cases compared with controls on the Rutter assessment scale (cases $4.2 \%$ vs controls $2.4 \%$ ) and the modified Conners scale (cases $4.8 \%$ vs controls $4.8 \%$ ) were not significantly different.

\section{PREVALENCE OF BEHAVIOURAL DISORDERS AT} AGES 8 AND 14 YEARS

Figure 2 shows the school derivation of the pairs for whom longitudinal data were obtained. The longitudinal comparison is limited to groups 1 and 2 (fig 2) - that is, the pairs for whom the same control child was assessed at age 8 and at age 14 years. This longitudinal comparison was thus limited to $132(79 \%)$ out of the original 167 matched case/control pairs.

The longitudinal comparison of the parent and teacher assessments are shown in table 2. After excluding those with missing data, the parental assessment of both cases and controls shows a non-significant reduction in the prevalence of behavioural problems at age 14 compared with age 8 years. For the index cases, comparable data were $33 \%(38 / 114)$ at age 8 years reduced to $24 \%(28 / 116)$ at age 14 years. The controls showed a significant reduction from $20 \%(23 / 113)$ to $9 \% 10 / 111 ; \mathrm{p}=0.03$. In contrast, the teacher assessment shows almost no change in the prevalence of behavioural problems among cases or controls between the ages of 8 and 14 years; $28 \%$ (34/120) when aged 8 years to $25 \%(30 / 119)$ when aged 14 years for the cases and $9 \%(11 / 121)$ to $10 \%$ $(12 / 126)$ for the controls.

Table 2 shows that, on the parental assessment, $12 \%(14 / 114)$ of the cases and $5 \%$ (5/111) of the controls had a behavioural problem at both 8 and 14 years of age. This differ-

Table 2 Longitudinal change in behaviour problems in index cases and controls assessments at ages 8 and 14 years

\begin{tabular}{lccc}
\hline \multirow{2}{*}{$\begin{array}{l}\text { Behavioural problem } \\
\text { at 8 years }\end{array}$} & \multicolumn{3}{c}{ Behavioural problem age 14 years } \\
\cline { 2 - 4 } & Absent & Present & Total \\
\hline Parent assessments in index cases & & \\
Absent & 64 & 12 & 76 \\
Present & 24 & 14 & 38 \\
Total & 88 & 26 & $114^{\star}$ \\
Teacher assessments in index cases & & \\
Absent & 70 & 16 & 86 \\
Present & 19 & 14 & 33 \\
Total & 89 & 30 & $119 \dagger$ \\
Parent assessments in controls & & & \\
Absent & 87 & 3 & 90 \\
Present & 14 & 5 & 19 \\
Total & 101 & 8 & $109 \ddagger$ \\
Teacher assessments in controls & & \\
Absent & 105 & 5 & 110 \\
Present & 9 & 2 & 11 \\
Total & 114 & 7 & 1219 \\
\hline
\end{tabular}

${ }^{\star}$ Missing data 18 cases

†Missing data 13 cases

$\ddagger$ Missing data 23 cases

ๆMissing data 11 cases 
Table 3 Longitudinal change in prevalence of hyperactivity in cases and controls aged 8 and 14 years

\begin{tabular}{|c|c|c|c|c|c|c|}
\hline \multirow[b]{3}{*}{ Age 8} & \multicolumn{6}{|l|}{ Age 14} \\
\hline & \multicolumn{3}{|l|}{ Rutter } & \multicolumn{3}{|l|}{ Connors } \\
\hline & $\begin{array}{l}\text { Hyper- } \\
\text { activity } \\
\text { absent }\end{array}$ & $\begin{array}{l}\text { Hyper- } \\
\text { activity } \\
\text { present }\end{array}$ & Total & $\begin{array}{l}\text { Hyper- } \\
\text { activity } \\
\text { absent }\end{array}$ & $\begin{array}{l}\text { Hyper- } \\
\text { activity } \\
\text { present }\end{array}$ & Totalt \\
\hline \multicolumn{7}{|l|}{ Cases } \\
\hline Hyper-activity absent & 104 & 3 & $107(82 \%)$ & 100 & 5 & $105(91 \%)$ \\
\hline Hyper-activity present & 20 & 3 & $23(18 \%)$ & 9 & 1 & $10(9 \%)$ \\
\hline Total ${ }^{\star}$ & $124(95 \%)$ & $6(5 \%)$ & $130(100 \%)$ & $109(95 \%)$ & $6(5 \%)$ & $115(100 \%)$ \\
\hline \multicolumn{7}{|l|}{ Controls } \\
\hline Hyper-activity absent & 122 & 1 & $123(94 \%)$ & 110 & 4 & $114(90 \%)$ \\
\hline Hyper-activity present & 7 & 1 & $8(5 \%)$ & 9 & 3 & $12(10 \%)$ \\
\hline Total & $129(98 \%)$ & $2(2 \%)$ & $131 \ddagger(100 \%)$ & $119(94 \%)$ & $7(6 \%)$ & $126-(100 \%)$ \\
\hline
\end{tabular}

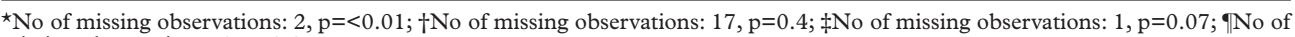
missing observations: $6, p=0.3$

ence was marginally significant; Fisher's exact test, $p=0.05$. The teacher's assessment showed that the behavioural problem was persistent in $12 \%(14 / 119)$ of the cases and in $2 \%(2 / 111)$ of the controls, a highly significant difference; $\mathrm{p}<0.01$.

CHANGE IN THE PREVALENCE OF HYPERACTIVITY AT AGES 8 AND 14 YEARS

The longitudinal change in the prevalence of hyperactivity is shown in table 3. According to the Rutter criterion, there was a highly significant reduction in hyperactivity among the cases, from $18 \%(23 / 130)$ when aged 8 years, to $5 \%(6 / 130)$ at age 14 years; $p<0.01$. The controls also showed a reduction in hyperactivity from $8 / 131(5 \%)$ to $2 / 131(2 \%)$, but the difference did not quite reach significance; $\mathrm{p}=0.07$.

Applying the Connors criterion for hyperactivity, neither the cases nor the controls showed a significant change in the prevalence of hyperactivity (table 3 ).

POPULATION ATTRIBUTABLE RISK OF LOW BIRTHWEIGHT INFANTS TO BEHAVIOURAL PROBLEMS

Based on the data from this study and national birthweight statistics, the population attributable risk made by low birthweight infants to behavioural problems can be estimated very approximately. In a birth cohort of 100000 infants about $1000(1 \%)$ will be of birthweight $\leqslant 1500$ g, 5000 ( $5 \%$ ) will be of birthweight 1501-2500 g, and $94000(6 \%)$ will weigh $\geqslant 2500$ g. At current birthweight specific mortalities, about $800(80 \%)$ of the $<1500$ g group, $4500(95 \%)$ of the $1501-2500 \mathrm{~g}$ group, and $90000(95 \%)$ of the $>2500$ group will survive to adolescence. Those of $<1500 \mathrm{~g}$ birthweight will account for about 72 cases of behavioural problems (based on a prevalence of $9 \%$ from cases in this study where parents and teacher questionnaires were concordant for the presence of behavioural problems). Similarly, those of birthweight $>2500 \mathrm{~g}$ will account for 2700 cases (based on a prevalence of 3\% in controls in this study). Data on those of birthweight 1500-2499 g are not available, but assuming a prevalence between that of the very low and the normal birthweight groups, there will be about $5 \%$ or 225 cases. Although the infants of $\leqslant 1500$ g birthweight are at considerably increased relative risk of behavioural problems compared with those of normal birthweight, the population attributable risk of a behavioural problem is only about $2.5 \%$. In terms of the overall prevention of behavioural problems, focusing on those adolescents who were of low birthweight is of limited value.

\section{Discussion}

The Rutter parent and teacher questionnaires are screening and not diagnostic instruments. Nevertheless, they have acceptable inter-rater and re-test reliabilities ${ }^{20}{ }^{21}$ and have been used to assess the prevalence of psychiatric problems in children. The cutoff point of the Rutter questionnaire score has been validated using children attending psychiatric interviews as criterion standards. ${ }^{202125}$

The main observation of the study is that, in early adolescence, low birthweight children have a significantly higher prevalence of behavioural problems, as determined by both parents and teachers, than their normal birthweight controls. Anecdotally, some mothers of the cases who had spent time in the neonatal intensive care unit commented that they had not achieved the same rapport with the case child as they had with siblings. A failure of mother-child bonding may, therefore, have contributed to the higher prevalence of behavioural problems in the low birthweight cohort.

Although the initial matching of cases and controls was by school, in order to minimise social and economic differences, those differences that were observed favoured the controls. It is possible, therefore, that the persisting socioeconomic inequalities could account for the difference in the prevalence of behavioural disorders in cases and controls. Alternatively, the cases made more frequent use of various medical services than the controls. Initially, most of the cases were admitted to neonatal intensive care and subsequently they were more frequent attenders at hospital as inpatients and outpatients and visited the family practitioner more often than did the control children. The increased parental anxiety associated with more frequent health service use may interact with the child's psychological development - a cycle of parental anxiety leading to behavioural problems, producing further anxiety.

The increased prevalence of conduct and emotional problems in low birthweight chil- 
dren is clinically important. A recent long term follow up of a cohort of infants born in 1946 found that adolescent emotional instability and conduct problems were associated with various causes of premature death, specifically accidental and suicide deaths. ${ }^{26}$

Furthermore, the observation that the teachers' perception of the prevalence of abnormal behaviour in the children, irrespective of whether they were cases or controls, was almost unchanged between the ages of 8 and 14 years. In contrast, parental perception was of a reduction in the prevalence of abnormal behaviour between the ages of 8 and 14 years. This was an unexpected observation as the teenage years are recognised as a time when parental-child tensions arise. Although the change did not reach significance and caution must be exercised in its interpretation, nevertheless, it may indicate a changing ability of the parent to cope with childhood behaviour. Alternatively, parental perception of a decrease in behavioural problems in both cases and controls in adolescence may reflect a shortcoming of the measuring instrument. The Rutter questionnaires were developed to identify behavioural problems in 11 year olds, and their validity for use among adolescents has not been established.

We thank the young participants, their parents, and school staff for excellent cooperation throughout the study, and the British Heart Foundation for funding.

1 Alberman E. Stillbirths and neonatal mortality in England and Wales by birthweight 1953-71. Health Trends 1974 6:14-17.

2 Hack M, Merkatz IR, Jones PK, Fanaroff AA. Changing trends of neonatal and postneonatal deaths in very low birthweight infants. Am $\mathcal{F}$ Obstet Gynecol 1980;137:797800.

3 Pharoah POD, Alberman ED. Mortality of low birthweight infants in England and Wales 1953-1979. Arch Dis Child infants in Englan $1981 ; 56: 86-9$.

4 Alberman E, Botting B. Trends in prevalence and survival of very low birthweight infants, England and Wales: 1993-7. Arch Dis Child 1991;66:1304-8.

5 Cooke RWI. Trends in preterm survival and incidence of cerebral haemorrhage 1980-89. Arch Dis Child 1991;66:403-7.

6 Powell TG, Pharoah POD, Cooke RWI. Survival and morbidity in a geographically defined population of low birthweight infants. Lancet 1986;i:539-43.
7 Wariyar U, Richmond S, Hey E. Pregnancy outcome at 24-31 weeks' gestation: neonatal survivors. Arch Dis Child 1989;64:678-86.

8 Roussounis SH, Hubley PA, Dear PRF. Five-year-follow-up of very low birthweight infants: neurological and psychological outcome. Child Care Hlth Dev 1993;19:45-59.

9 Pharoah POD, Stevenson CJ, Cooke RWI, Stevenson RC. Prevalence of behaviour disorders in low birthweight infants. Arch Dis Child 1994;70:F271-F4.

10 Rosenbaum P, Saroj S, Szatmari P, Hoult L. Vineland Adaptive Behavior Scales as a summary of functional outcome of extremely low birthweight children. Dev Med Child Neurol 1995; 37:577-86.

11 Mutch L, Leyland A, McGee A. Patterns of neuropsychological function in a low birthweight population. Dev Med Child Neurol 1993;35:943-56.

12 Khadilkar V, Tudehope D, Burns Y, O'Callaghan M, Mohay $H$. The long-term neurodevelopmental outcome for very low birthweight (VLBW) infants with 'dystonic' signs at 4 low birthweight (VLBW) infants with 'dystonic' signs at

13 Dammann O, Walther H, Allers B, et al. Development of a regional cohort of very low birthweight children at six years: cognitive abilities are associated with neurological disability and social background. Dev Med Child Neurol 1996;38:97-108.

14 Weisglas-Kuperus N, Koot HM, Baerts W, Fetter WPF, Sauer PJJ. Behaviour problems of very low birthweight children. Dev Med Child Neurol 1993;35:406-16.

15 Sommerfelt K, Troland K, Ellertson B, Markestad T. Behavioural problems in low birthweight preschoolers. Dev Med Child Neurol 1996;38:927-40.

16 Manzke H. Unvermeidbare Auswirkungen intensivneonatologischer aktivitäten auf das spätere Schicksal neonatologischer aktivitäten auf das spatere Schicksal neonatal intensive care on the later development of neonatal intensive care on the later development of 1992;196:165-72

17 Ornstein M, Ohlsson A, Edmonds J, Asztalos E. Neonatal follow-up of very low birthweight/extremely low birthweight infants to school age: a critical review. Acta Pediatr Scand 1991;80:741-8.

18 Pharoah POD, Stevenson CJ, Cooke RWI, Stevenson RC. Clinical and subclinical deficits at 8 years in a geographically defined cohort of low birthweight infants. Arch Dis Child 1994;70:F264-F70.

19 Rutter MA. A children's behaviour questionnaire for completion by teachers: preliminary findings. F Child Psychol Psychiatry 1967;8:1-11.

20 Rutter M, Tizard J, Whitmore K, eds. Education, health and behaviour. London: Longman, 1970.

21 Rutter M, Tizard J, Yule W, Graham P, Whitmore K. Research report :Isle of Wight studies, 1964-1974. Psychol Med 1976; 6:313-32.

22 Conners CK. A teacher rating scale for use in drug studies with children. Am f Psychiatry 1969;126:884-8.

23 Taylor E, Sandberg S. Hyperactive behaviour in English schoolchildren: a questionnaire survey. 7 Abnorm Child Psychol 1984;12:143-56.

24 Pharoah POD, Stevenson CJ, West CR. Association of blood pressure in adolescence with birthweight. Arch Dis Child 1998;79:F114-18.

25 Rutter R, Cox A, Tupling C, Berger M, Yule W. Attainment and adjustment in two geographical areas 1:The prevalence of psychiatric disorder. Br $\mathcal{F}$ Psychiatry 1975; 126:493-509.

26 Neeleman J, Wessely S, Wadsworth M. Predictors of suicide, accidental death, and premature natural death in a general-population birth cohort. Lancet 1998;351:93-7. 